\title{
Comparative immunological studies on some single and combined live attenuated vaccines in poultry
}

\author{
Hanan M. El-Zahed*, Susan S. El-Mahdy, N. A. Sherif, Amal A. Sayed, Anhar \\ Abdel Moety \\ Central Laboratory for Evaluation of Veterinary Biologics, Abbasia, Cairo, Egypt
}

\begin{abstract}
In a trial for comparison between the efficiency of single fowl pox (FP) vaccination and the efficiency of each combined FP and Avian encephalomyelitis (AE) vaccination and simultaneous vaccination with FP and Reo and with FP and Chicken anemia virus (CAV) vaccines our conclusion was that there is no antagonistic reaction between FP virus strain and each AE, Reo and $\mathrm{CA}$ viruses strains. In addition, humoral immune response against $\mathrm{AE}$ virus strain in case of combined $A E+F P$ vaccination is markedly potent than that in case of single $A E$ vaccination, more over the value of average IID $_{50}$ of $A E$ virus strain in several batches of combined $A E+F P$ vaccines is significantly higher at $\mathbf{P} \geq \mathbf{0 . 0 5}$ than that in several batches of single $\mathrm{AE}$ vaccines. On the other hand, immune response against FP virus strain and Reo virus strain in case of simultaneous vaccination with FP and Reo vaccines is higher than that in case of single FP vaccination and single Reo vaccination. Consequently, it is advisable to use combined live attenuated AE+FP vaccine instead of vaccination with single FP and AE separately. Also, application of simultaneous vaccination with FP and Reo vaccines is advisable as it is proved to be more beneficial than vaccination with each vaccine separately specially in case of that FP vaccine of low potency.
\end{abstract}

Some viral poultry diseases cause very high rates of mortality or great decrease in production resulted in dramatic economic losses. However avian encephalomyelitis (AE) and fowl pox (FP) are among viral diseases that cause considerable economic losses to poultry due to the drop in egg production in laying hens and retarded growth in young chickens (Tripathy, 1989), Reovirus infection causes $100 \%$ morbidity (Frederick et al., 1999). This disease causes economic losses as a result of crippling, viral arthritis, reduced marketability of the affected birds, diminished weight gain and poor food conversion (Dabson and Glisson, 1992). Also chicken anemia virus (CAV) infection causes immunosuppression thus it causes serious economic losses in commercial poultry production (Nova and Ragland, 2001) beside inadequate response to vaccination programs (Franz and Coral, 2003). Consequently vaccination against these viral diseases became necessary specially that using combined vaccines which are preferable as they have advantage of providing protection against more than one disease, reducing vaccination expense, saving time and labor costs besides reducing the stress reactions. Also, simultaneous vaccination help in improving the immune response against to

* Corresponding author. Tel.: +202 3422505;

Fax: +202 3449204

E-mail address: clevb@tedata.net.eg

(Hanan M. El-Zahed) vaccines which simultaneously applied especially if fowl pox vaccine included as it was known as an immunostimulant (Gergis et al., 1994; Sherif et al., 2002).

So, the objective of this study was to compare between the efficiency of single fowl pox vaccination and the efficiency of each combined $\mathrm{AE}+\mathrm{FP}$ vaccination; simultaneous vaccination with $\mathrm{FP}$ and Reo vaccine and simultaneous vaccination with $\mathrm{FP}$ and CAV vaccine, in addition to determine the possibility of interference or antagonistic reactions between the two viruses antigens in combined and simultaneous vaccination through the following: (1) Estimation of the egg infective dose fifty $\left(E_{50}\right)$ for $\mathrm{AE}$ and $\mathrm{FP}$ virus strain in several batches of single $\mathrm{AE}$ and $\mathrm{FP}$ vaccines in comparison with that in several batches of combined $\mathrm{AE}+\mathrm{FP}$ vaccines using $\mathrm{SPF}$ embryonated chicken eggs (ECE), (2) Investigation of immune response against FP virus in different vaccinated chickens groups by detecting the percentage of chickens showing FP post vaccination lesions (takes) and protection percentage in each group post challenge with virulent FP virus, (3) Evaluation of chicken humeral immune response to $\mathrm{AE}$, Reo and CA viruses in chickens vaccinated groups by application of commercial ELISA kit for 
detection of antibodies against $\mathrm{AE}$, Reo and CAV.

\section{Materials and methods}

SPF embryonated chicken eggs (ECE). 1560, 12 days old SPF ECE were used for titration of fowl pox vaccines and 2550, 6 days old SPF $\mathrm{ECE}$ were used for titration of $\mathrm{AE}$ vaccines. These eggs were supplied by Koum Osheim SPF Farm, Fayoum Governorate, Egypt.

Chickens. Two hundreds and ten (210) SPF chickens of 6 weeks old(sutable age for FP" AE "Reo and CAV vaccination according to the manufacturer instruction) were obtained from SPF Farm, Koum Osheim, Fayoum governorate, Egypt and reared under hygienic measures in isolated cages.

Vaccines. These vaccines include 5 commercial imported ready prepared vaccines.

Live attenuated strain of fowl pox virus was in two different vaccines.

$\mathrm{FP}$ vaccine of $\mathrm{EID}_{50} /$ dose $>10^{4.2}$ (Intervet Co.).

$\mathrm{FP}$ vaccine of its $\mathrm{EID}_{50} /$ dose was $10^{2.8}$ (Intervet Co.).

Live attenuated strain of $A E$ virus of $\mathrm{EID}_{50} /$ dose $10^{3.0}$ (IZO Co.).

Live attenuated Reovirus of $\mathrm{TCID}_{50} /$ dose $10^{4.0}$ (Intervet Co.).

Live attenuated CAV of $\mathrm{TCID}_{50} /$ dose $10^{3.6}$ (Intervet Co.).

Combined bivalent live attenuated $\mathrm{AE}$ and $\mathrm{FP}$ vaccine of $\mathrm{EID}_{50}$ /dose $10^{4.2}$ for $\mathrm{FP}$ virus and $\mathrm{EID}_{50} /$ dose $10^{3.7}$ for $\mathrm{AE}$ virus (Intervet Co.).

Virulent strain. Egyptian virulent FP virus was used as challenge virus of a titre $10^{6.0} \mathrm{EID}_{50} / \mathrm{ml}$ and used in a dose of $10^{3.0} \mathrm{EID}_{50} / \mathrm{bird}$. It was isolated and identified by (Saban, 1954).

Experimental Design. Chickens were divided into eight groups as follow:

Group (1). Consisted of 45 chickens divided into two subgroups:

Subgroup (1A). Containing 15 chickens were vaccinated with single FP vaccine of EID50/dose $>10^{4.2}$ via the wing web route in the right wing.

Subgroup (1B). Consisted of 30 chickens were vaccinated with single FP vaccine of EID50 $/$ dose $10^{2.8}$ through the same route in subgroup $1 \mathrm{~A}$.

Group (2). Containing 15 chickens were vaccinated with live attenuated $\mathrm{AE}$ vaccine through drinking water.

Group (3). Containing 30 chickens were vaccinated with combined bivalent attenuated FP and $\mathrm{AE}$ vaccine via the wing web in right wing.

Group (4). Consisted of 15 chickens were vaccinated with live attenuated Reovirus vaccine in a dose of $0.2 \mathrm{ml} /$ bird through the subcutenious $(\mathrm{s} / \mathrm{c})$ rout

Group (5). Thirty chickens were vaccinated simultaneously with live attenuated Reo vaccine $\left(0.2 \mathrm{ml} / \mathrm{bird} \mathrm{s} / \mathrm{c}\right.$ ) with $\mathrm{FP}$ vaccine( of $10^{2.8}$ $\mathrm{EID}_{50} /$ dose) via wing web route in right wing.

Group (6). Fifteen chickens were vaccinated with live attenuated CAV vaccine using $0.5 \mathrm{ml} / \mathrm{bird}$ inoculated intramuscularly (IM).

Group (7). Thirty chickens were vaccinated simultaneously with CAV vaccine(using $0.5 \mathrm{mi} /$ bird inoculated IM) withFP vaccine (of $>10^{2.8} \mathrm{EID}_{50} /$ dose) through wing web in the right wing.

Group (8). Thirty chickens were kept unvaccinated in separate cages as negative control birds.

The vaccines were administered as recommended by manufacturer instruction.

Samples. Ten random blood samples were collected from each chicken group weekly allover the experimental period (8-10 weeks). The obtained serum samples were tested for evaluation of the humoral immune response against $\mathrm{AE}$ virus in groups 2 and 3, Reovirus in groups 4 and 5 and CAV in groups 6 and 7 Using ELISA.

Enzyme linked immunosorbent assay (ELISA). ELISA kits for AE (catalog No. CK 123), for Reovirus (catalog No. CK 110) and for CAV (catalog No. 126) were supplied by Biocheck Co., Holland.

ELISA for detection of antibodies against $\mathrm{AE}$, Reo and CAV was carried out according to (Sharen and Tanock, 1988), (Giambrone et al., 1991), and (Myrna et al., 2003) respectively

Determination of percentage of chickens showing takes. It was carried out by examination of the site of FP vaccination (right wing web) in each group including groups of chickens vaccinated with $\mathrm{FP}$, combined $\mathrm{FP}+\mathrm{AE}$ (groups 1 and 3 respectively) and groups simultaneously vaccinated with $\mathrm{FP}+\mathrm{Reo}$ and $\mathrm{FP}+\mathrm{CAV}$ (groups 5 and 7 , respectively) (According to Code of Federal Regulations, 2006).

Challenge test. Three weeks post vaccination, ten chickens from each vaccinated groups $1,3,5$ and 7 and control group 8 were challenged with standard challenge dose of virulent fowl pox virus containing $10^{3.0} \mathrm{EID}_{50}$ /bird through wing web in the left wing, then the challenged birds were checked for takes at $10^{\text {th }}$ and $14^{\text {th }}$ day post challenge. 
Titration of single and combined bivalent vaccines of $\mathbf{F P}$ and $A \mathbf{E}$ virus. Titration of $A E$ vaccines (single $\mathrm{AE}$ and combined $\mathrm{AE}+\mathrm{FP}$ ) was done according to Code of Federal Regulations (2006) in 6 day old SPF ECE through the intrayolk route. At the third day from the beginning of hatching, hatched chicks in each dilution were examined for any symptoms related to AE virus and the $\mathrm{EID}_{50}$ was calculated according to Reed and Muench (1938). Titration of FP vaccines (single FP and combined $\mathrm{FP}+\mathrm{AE}$ ) was carried out in five 12 days old SPF ECE on chorioallantoic membrane (CAM). CAMs of eggs were examined at the $7^{\text {th }}$ day post inoculation for presence of pock lesions in each dilution. $\mathrm{EID}_{50}$ was calculated according to (Reed and Muench,1938).

\section{Results and Discussion}

Table (1) showed that the average $\log _{10}$ of $\mathrm{EID}_{50}$ of $\mathrm{AE}$ virus strain in fifteen batches of combined AE and FP vaccines was 3.92 which is significantly higher at $\mathrm{P} \geq 0.05$ than that in twenty two batches of single AE vaccines (3.29). In addition, AE ELISA antibody geometric mean titre (GMT) in combined AE and FP vaccinated chickens (group 3) was markedly higher than the corresponding GMTs in the single AE vaccinated (group 2) through the ten week post vaccination (WPV) (Table 2 and Fig. 1).

It is clear that the humoral immune response against $\mathrm{AE}$ virus strain and the $\mathrm{EID}_{50}$ of $\mathrm{AE}$ virus strain in case of combined $\mathrm{AE}$ and $\mathrm{FP}$ vaccination is higher than that in case of single $\mathrm{AE}$ vaccination. This finding could be attributed to the immune stimulant effect of FP virus is in agreement with that obtained by Gergis et al., (1994) and Sherif et al., (2002).

On the other hand, percentage of chickens showing FP vaccination lesions in combined $\mathrm{AE}$ and FP vaccinated chickens (group 3) was $91.6 \%$ which was nearly equal or slightly lower than that in single FP vaccinated group (1A) (100\%) as shown in Table (5).

These findings comes parallel to those in table (6) which showed that the protection percentage at $2^{\text {nd }}$ week post challenge with virulent FP virus at the $3^{\text {rd }} \mathrm{WPV}$ in combined $\mathrm{AE}+\mathrm{FP}$ vaccinated group (3) was slightly lower $(90 \%)$ than that in single FP vaccinated group (1A) $(100 \%)$. In addition, table (1) explains that the average $\mathrm{EID}_{50}$ of FP strain in 27 batches of single FP vaccines and in fifteen batches of combined $\mathrm{AE}+\mathrm{FP}$ vaccines is nearly equal as they are 3.81 and 3.84, respectively. This previous findings indicates that the protection percent and percent of chicken showing FP vaccination lesion and $\mathrm{EID}_{50}$ of $\mathrm{FP}$ strain in case of combined $\mathrm{AE}+\mathrm{FP}$ vaccination is nearly equal to that in case of single FP vaccination.

In conclusion, there is no antagonistic reaction between the two antigens $\mathrm{AE}$ and $\mathrm{FP}$ when combined as live vaccine. Moreover, FP acts as immunostimulant to $\mathrm{AE}$ virus. This conclusion encouraging application of combined vaccination in the field as combined vaccines has many advantages than single one (Abdel Wanis et al., 1999; Afaf et al., 1999 and Sherif et al., 2002).

In simultaneous vaccination, experiment at first we used FP vaccine with $>10^{4.2} \mathrm{EID}_{50}$ /dose for vaccination of 3 groups of chickens (single FP vaccinated group, FP and Reo vaccinated group, FP and CAV vaccinated group). The percentage of chickens showing takes and the protection percentage against FP challenge virus were the same in the above 3 groups (100\%). So, we repeated this experiment using another FP vaccine with $10^{2.8} \mathrm{EID}_{50} /$ dose which gave $70 \%$ protection in FP vaccinated chickens to enable us to differentiate between the above three groups. Table (5) illustrated that the The percentage of chickens showing FP vaccination lesions is $100 \%$ in simultaneously vaccinated group (5) with FP of $10^{2.8}$ EID $_{50} /$ dose and Reo. This percentage is higher than that in single FP vaccinated subgroup (1B) (it is 75\%). This result is in agreement with that in table (6) which illustrated that protection percentage at $2^{\text {nd }}$ week post challenge with virulent FP virus at $3^{\text {rd }} \mathrm{WPV}$ in the FP and Reo simultaneously vaccinated group (5) is $100 \%$ higher than that in the single FP vaccinated subgroup (1B) $(70 \%)$.

We repeat this challenge experiment twice and the same result was obtained on the other hand, table (3) showed that Reo ELISA antibody GMTs in single Reo vaccinated chickens (group 4) are slightly lower than that in simultaneous vaccinated chickens with FP and Reo vaccines (group 5) through the nine WPV. This titre in the two groups was protective (Thayer et al., 1986). The explanation of these findings showing that there is synergism between Reo and FP virus strains if used together in simultaneous vaccination. As the humoral immune response against Reovirus strain, percentage of chickens showing FP vaccination lesions and protection percentage against FP challenge are higher in FP and Reo simultaneously vaccinated group than that in single FP and single Reo vaccinated group. In addition, there is no antagonistic 
Table (1): Titres of $\mathrm{AE}$ and $\mathrm{FP}$ viruses $\left(\log _{10} \mathrm{EID}_{50}\right)$ in several batches of single and combined $\mathrm{AE}$ and $\mathrm{FP}$ vaccines.

\begin{tabular}{|c|c|c|c|c|}
\hline \multirow{3}{*}{ Vaccine type } & \multicolumn{4}{|c|}{ Virus Titre } \\
\hline & \multirow{2}{*}{ Single FP } & \multirow{2}{*}{ Single AE } & \multicolumn{2}{|c|}{ Combined AE+FP } \\
\hline & & & FP & $\mathbf{A E}$ \\
\hline \multirow{2}{*}{$\begin{array}{l}\text { Average } \log _{10} \operatorname{EID}_{50} / \text { dose } \\
\text { No. of vaccine batches }\end{array}$} & 3.81 & $3.29+0.37$ & 3.84 & $3.92+0.274$ \\
\hline & 27 & 22 & & 15 \\
\hline \multicolumn{5}{|c|}{$\begin{array}{l}\text { Fowl Pox. } \\
\text { Avian Encephalomyelitis. } \\
\text { Egg Infective Dose fifty. } \\
\text { Specific Pathogen Free. }\end{array}$} \\
\hline \multicolumn{5}{|c|}{$\begin{array}{l}\text { Table (2): AE ELISA antibody GMTs in chickens vaccinated with single AE vaccine and } \\
\text { combined AE and FP vaccines. }\end{array}$} \\
\hline \multirow{2}{*}{ Weeks post vaccination } & \multicolumn{4}{|c|}{ ELISA antibody titre GMT in chicken group } \\
\hline & Group (2) & Grol & & Group (8) \\
\hline 1 & 211 & & & 201 \\
\hline 2 & 241 & & & 355 \\
\hline 3 & 310 & & & 311 \\
\hline 4 & 625 & & & 320 \\
\hline 5 & 807 & & & 331 \\
\hline 6 & 1100 & & & 357 \\
\hline 7 & 1276 & & & 318 \\
\hline 8 & 1121 & & & 320 \\
\hline 9 & 1120 & & & 325 \\
\hline 10 & 930 & & & 326 \\
\hline
\end{tabular}

Group (2): Chickens vaccinated with single AE vaccine.

Group (3): Chickens vaccinated with combined AE and FP vaccine.

Group (8): Control unvaccinated chickens.

GMT: Geometric mean titres.

$\log _{10}$ titre $=1.1\left(\log _{10} \mathrm{SP}\right)+3.361$.

Titre $=$ Anti- $\log 10^{\mathrm{x}}$.

Titre of positive serum sample was $\geq 1071$.

Pre-vaccination AE ELISA antibody GMT = 106.

reaction between FP and Reo when inoculated simultaneously in chickens as Reo vaccine not interferes with many types of avian vaccines (Edison and Kleven, 1983, Giambrone and Hathcoock, 1991). Moreover, Reo vaccination improves the immune response against FP vaccination. This result encourages the application of simultaneous vaccination with Reo and FP vaccines specially in case of FP vaccines of low potency.

Table (4) explained that CAV ELISA antibody GMTs in simultaneously vaccinated chickens with FP and CAV vaccines (group 7) are slightly higher than the corresponding GMTs in single CAV vaccinated group (6) through the nines WPV. All titres in these groups were protective (Malo and Weingartan, 1995). On the other hand, percentage of chickens showing FP vaccination lesions in FP and CAV simultaneously vaccinated group (7) is $83.3 \%$ which is slightly higher than that in single low titre FP vaccinated group (1b) (75\%) (Table 5). This result is parallel to that in table (6) which showed that protection \% against FP challenge in simultaneously vaccinated group (7) with FP and CAV is $80 \%$ slightly higher than that in single FP vaccinated group (6) (it is $70 \%$ ).

It is concluded that there is no antagonistic reaction between $\mathrm{FP}$ and CAV virus strain if used in vaccination simultaneously. Moreover, FP stimulated slightly humoral immune response against CAV vaccine. On the other hand, live attenuated CAV vaccine is safe if inoculated simultaneously with FP vaccine and not cause immunosuppression (Hanan et al., 2008). Also, $\mathrm{CAV}$ vaccine not reverse to its virulence as mentioned by Todd et al., $(1995,1998)$.so, it could be concluded that FP virus strain not has antagonistic reaction with $\mathrm{AE}$, Reo or $\mathrm{CA}$ virus strains. Moreover, FP virus stimulates the 
immune response against $\mathrm{AE}$, Reo and $\mathrm{CAV}$ virus strains.

Table (3): Reo ELISA antibody GMTs in chickens vaccinated with Reo vaccine and simultaneously with FP and Reo vaccines.

\begin{tabular}{cccc}
\hline \multirow{2}{*}{ Weeks post vaccination } & \multicolumn{3}{c}{ ELISA antibody GMT of chicken group } \\
\cline { 2 - 4 } & Group (4) & Group (5) & Group (8) \\
\hline $\mathbf{2}$ & 4000 & 3390 & 464 \\
$\mathbf{3}$ & 5040 & 5108 & ND \\
$\mathbf{4}$ & 7800 & 7890 & 786 \\
$\mathbf{5}$ & 7144 & 7472 & ND \\
$\mathbf{8}$ & 5774 & 7380 & 642 \\
$\mathbf{9}$ & 6154 & 8371 & ND \\
\hline
\end{tabular}

Group (4): Chickens vaccinated with single Reo vaccine.

Group (5): Chickens simultaneously vaccinated with Reo and FP vaccines.

Group (8): Control unvaccinated chickens.

GMT: Geometric mean titres.

$\log _{10}$ titre $=1.1\left(\log _{10} \mathrm{SP}\right)+3.9$.

Titre $=$ Anti- $\log 10^{\mathrm{x}}$.

Titre of positive serum sample was $\geq 1352$.

Pre-vaccination Reo ELISA antibody GMT $=1120$.

Table (4): CAV ELISA antibody GMTs in chickens vaccinated with single CAV and simultaneously with CAV and FP vaccines.

\begin{tabular}{cccc}
\hline \multirow{2}{*}{ Weeks post vaccination } & \multicolumn{3}{c}{ ELISA antibody GMT of chicken group } \\
\cline { 2 - 4 } & Group (6) & Group (7) & Group (8) \\
\hline $\mathbf{2}$ & 2012 & 3672 & 186 \\
$\mathbf{4}$ & 3099 & 3947 & 193 \\
$\mathbf{6}$ & 4120 & 4327 & $\mathrm{ND}$ \\
$\mathbf{7}$ & 4662 & 4709 & 347 \\
$\mathbf{8}$ & 4781 & 4959 & $\mathrm{ND}$ \\
$\mathbf{9}$ & 7050 & 7523 & 366 \\
\hline
\end{tabular}

Group (6): Chickens vaccinated with single CAV vaccine.

Group (7): Chickens simultaneously vaccinated with CAV and FP vaccines.

Group (8): Control unvaccinated chickens.

GMT: Geometric mean titres.

$\log _{10}$ titre $=1.10\left(\log _{10} \mathrm{SP}\right)+3.361$.

Titre $=$ Anti- $\log 10^{\mathrm{x}}$.

Titre of positive serum sample was $\geq 724$.

Table (5): Percentage of chickens showing FP vaccination lesion (takes) in single FP vaccinated sub group (1A and 1B), Reo and FP simultaneously vaccinated group, CAV and FP simultaneously vaccinated group and in combined $\mathrm{AE}$ and $\mathrm{FP}$ vaccinated group.

\begin{tabular}{|c|c|c|c|}
\hline Chicken groups & $\begin{array}{l}\text { Types of vaccines/method of } \\
\text { vaccination }\end{array}$ & $\begin{array}{c}\text { No. of +ve } \\
\text { chickens/Total No. }\end{array}$ & $\begin{array}{c}\text { \% of chickens showing } \\
\text { takes at } 10^{\text {th }} \text { DPV }\end{array}$ \\
\hline $\mathbf{1 A}$ & Single high titre FP & $12 / 12$ & $100 \%$ \\
\hline 1B & Single low titre FP & $9 / 12$ & $75 \%$ \\
\hline 5 & $\begin{array}{l}\text { Simultaneously vaccinated with } \\
\text { Reo and FP }\end{array}$ & $12 / 12$ & $100 \%$ \\
\hline 7 & $\begin{array}{l}\text { Simultaneously vaccinated with } \\
\text { CAV and FP }\end{array}$ & $10 / 12$ & $83.3 \%$ \\
\hline 3 & Combined AE and FP & $11 / 12$ & $91.6 \%$ \\
\hline
\end{tabular}

Subgroup (1A): Chickens vaccinated with single FP vaccine with $\mathrm{EID}_{50} /$ dose $=>10^{4.2}$ (high titre $\mathrm{FP}$ vaccine).

Subgroup (1B): Chickens vaccinated with single live attenuated FP vaccine with $\mathrm{EID}_{50} / \mathrm{dose}=10^{2.8}$ (low titre FP vaccine).

Group (5): Chickens simultaneously vaccinated with live attenuated Reo vaccine and FP vaccine which used in subgroup 1B.

Group (7): Chickens simultaneously vaccinated with live attenuated CAV vaccine and FP vaccine which used in subgroup 1B.

Group (3): Chickens vaccinated with combined bivalent live attenuated AE+FP vaccine. 
* +ve chickens: Chickens showing FP vaccination lesions (takes) at site of vaccination (right wing).
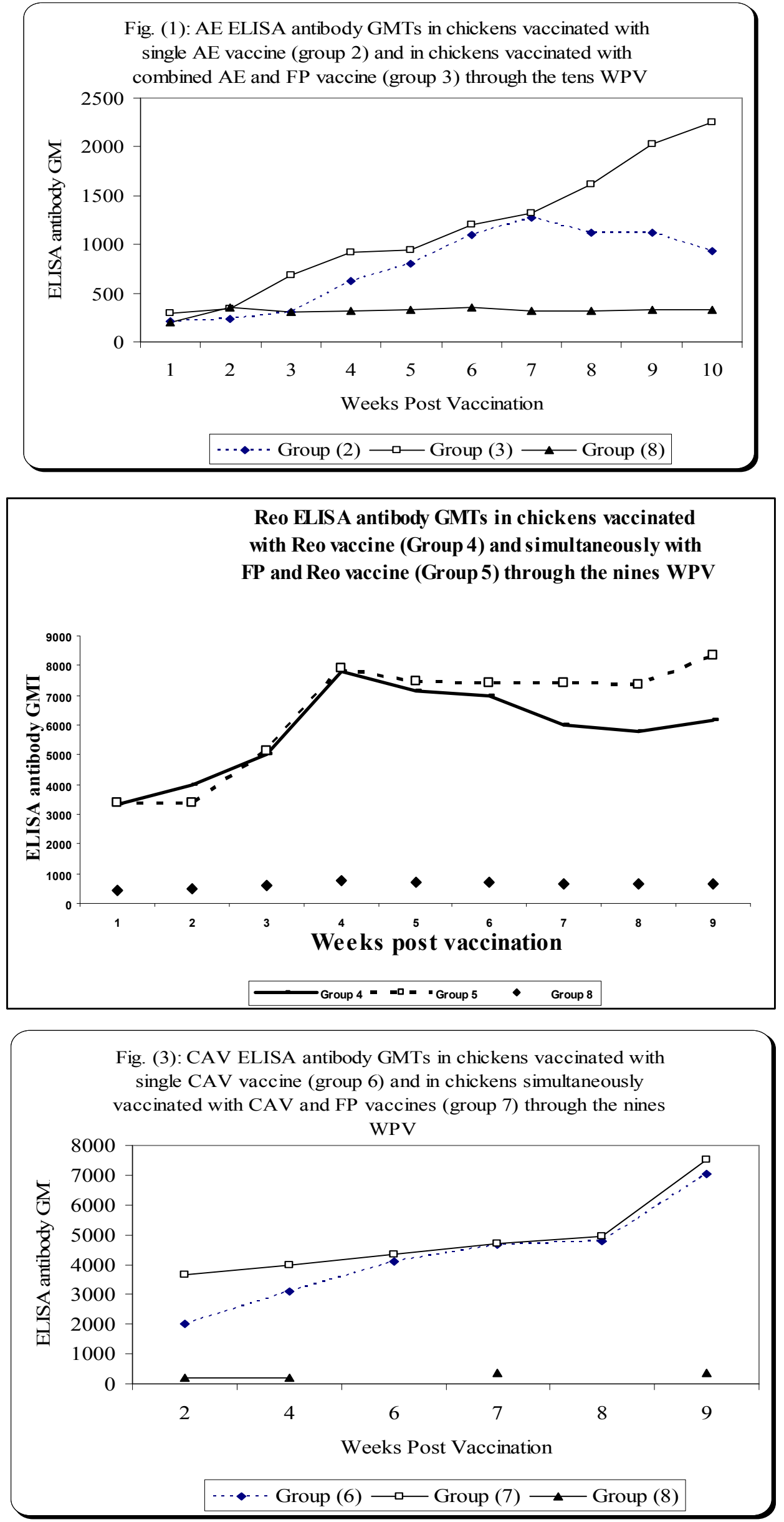
Table (6): Protection percentage at $2^{\text {nd }}$ week post challenge with virulent FP virus at $3^{\text {rd }}$ WPV in single FP vaccinated subgroup 1Aand 1B, Reo and FP simultaneously vaccinated group, CAV and FP simultaneously vaccinated group and combined $\mathrm{AE}$ and $\mathrm{FP}$ vaccinated group

\begin{tabular}{|c|c|c|c|c|}
\hline & $\begin{array}{l}\text { icken } \\
\text { oups }\end{array}$ & $\begin{array}{c}\text { Types of vaccines/method } \\
\text { of vaccination }\end{array}$ & $\begin{array}{c}\text { No. of +ve chickens/Total } \\
\text { No. }\end{array}$ & $\begin{array}{l}\% \text { of chickens showing takes at } \\
10^{\text {th }} \text { DPV }\end{array}$ \\
\hline \multirow{2}{*}{1} & $1 \mathrm{~A}$ & Single high titre FP & $10 / 10$ & $100 \%$ \\
\hline & 1B & $\begin{array}{l}\text { Single low titre FP } \\
\text { Simultaneously }\end{array}$ & $7 / 10$ & $70 \%$ \\
\hline 5 & & $\begin{array}{l}\text { vaccinated with Reo and FP } \\
\text { Simultaneously }\end{array}$ & $10 / 10$ & $100 \%$ \\
\hline 7 & & vaccinated with CAV and FP & $8 / 10$ & $80 \%$ \\
\hline 3 & & Combined $\mathrm{AE}$ and $\mathrm{FP}$ & $9 / 10$ & $90 \%$ \\
\hline 8 & & Control unvaccinated & $0 / 10$ & $0 \%$ \\
\hline
\end{tabular}

Subgroup (1A): Chickens vaccinated with single FP vaccine its $\mathrm{EID}_{50} /$ dose $=>10^{4.2}$ (high titre FP vaccine).

Subgroup (1B): Chickens vaccinated with single live attenuated FP vaccine its $\mathrm{EID}_{50} /$ dose $=10^{2.8}$ (low titre FP vaccine).

Group (5): Chickens simultaneously vaccinated with live attenuated Reo vaccine and FP vaccine which used in subgroup 1B. Group (7): Chickens simultaneously vaccinated with live attenuated CAV vaccine and FP vaccine which used in subgroup 1B.

Group (3): Chickens vaccinated with combined bivalent live attenuated AE+FP vaccine.

Group (8): Control unvaccinated chickens.

* +ve chickens: Chickens showing symptoms related to FP infection or challenge lesions (takes) at site of challenge (left wing).

\section{References}

Abd El-Wanis, N.A.; Madkour, M. S.; Abd El-Khalik, M. and Mervat A. El-Komy (1999): Trials for preparation of a combined live vaccine against duck virus hepatitis and duck virus enteritis (duck plague). Alex. J. Vet. Sci., 15 (3): 617-626.

Afaf, H. A.; Khodeir, M. H. and Aboul El-Kheir, M.A. (1999): Studies to prepare an inactivated vaccine against Gumboro and Reo viruses. J. Vet. Med. Res., 29:43, 1 (1). Code of Federal Regulation (2006): Part 1 to 199, Animal and Animal Products. Part 113.326, 113.325.

Dabson, K. N. and Glisson, J. R. (1992): Economic impact of documented case of reovirus infection in broiler breeders. Avian Dis., 36: 788-791.

Davison, S.; Ginggerich, E. N.; Casavant and Exkroade, R.J. (2006): Evaluation of the efficacy of a live fowl pox vectored infectious laryngotracheitis / avian encephalomyelitis vaccine against ILT viral challenge. Avian Dis., 50 (1): 50-54.

Eidson, C. S. and Kleven, S. H. (1983): Simultaneous vaccination of one day old broiler chicken with tenosynovitis virus and turkey herpes virus vaccine. Poult. Sci., 64 (11): 2081-2086.

Sommer, F. and Cardona, C. (2003): Chicken anaemia virus in broiler flocks. Avian Dis., 47: 1466-1473.

Frederick, A. M.; Paul, E.; Gibbs, J.; Marian, C.; Harzinek and Michae, J. Studdert (1999): Veterinary Virology, Third Edition, Chapter 24, Reoviridae, pp. 392397.

Gergis, S. M.; Soliman, S. M.; Soliman, I. A. A.; Gorgi, S. F. and Michael, A. (1994): Combined vaccination against fowl cholera and fowl pox diseases. J. Egypt. Assoc. Immunol., 1: 104-106.

Giambrone, J. J.; Hatchcock, T. L. and Lockaby, S. B. (1991): Effect of a live reovirus vaccine on productive performance of broiler breeder hens and development of viral tenosynovitis in progeny. Avian Dis., 35 (2): 378-383.

Hanan M. El-Zahed; Abdel Moneim, A. A.; Khedr, A. A.; El-Ebiary, E. A.; Abdel Latif, W. S. and Reda, I. M.
(2008): Immune response to a live attenuated chicken anemia virus (CAV) vaccine. The absence of virus shedding. Egypt. J. Virol., 5 (1): 304-321.

Malo, A. and Weingarten, M. (1995): Determination of the minimum protective neutralizing antibody titre to CAV in adult chickens. Intervet VSD Newletter, 11: 1-5.

Miller, M. M.; Ealey, K. A.; Oswold, W. B. and Schat, K. A. (2003): Detection of chicken anaemia virus DNA in embryonal tissues and egg shell membrane. Avian Dis., 47: 662-671.

Nova, K. R. and Ragland, W. L. (2001): Competitive DNA hybridization in microtitre plates for chicken anaemia virus. Mol. Cell Probes, 15 (1): 1-11.

Reed, L. J. and Muench, H. (1938): A simple method of estimating 50 percent end points. Am. J. Hyg., 27: 493-497.

Sabban, M. S. (1984): Fowl pox and the use of the whole embryo vaccine in controlling the disease in Egypt. Am. J.Vet. Res., 15:133.

Shafren, D. R. and Tannock, G.A. (1988): An enzyme linked immunosorbent assay for the detection of avian encephalomyelitis virus antigens. Avian Dis., 32 (2): 209214.

Sherif, N. A.; El-Ebiary E. A.; Soliman, S. M.; Michael, A.; Omar, L. M. and El-Makaky, H. (2002): A trial for preparation and evaluation of live attenuated combined avian encephalomyelitis and fowl pox vaccine in comparison with imported one. Vet. Med. J., Giza, 50 (4): 1011-1019.

Thayer, S. G.; Villegas, P. and Fletcher, O. J. (1986): Comparison of two commercial enzyme linked immunosorbent assay and conventional method for avian serology. Avian Dis., 31: 120-125.

Todd, D.; Connor, T. J.; Calvert, V. M.; Creelan, J. L.; Meehan, B. M. and McNulty, M. S. (1995): Molecular cloning of an attenuated chicken anemia virus isolate following repeated cell culture passage. Avian Pathol., 24: 171-187.

Todd, D.; Connor, T. J.; Creelan, J. L.; Borghmans, B. J.; Calvert, V. M. and McNulty, M.S. (1998): Effect of 
multiple cell culture passages on the biological behaviour of chicken anemia virus. Avian Pathol., 27: 74-79.

Tripathy, D. N. (1989): Pox. In Purchase, H.G.; L.H. Arp, C.H. Damermuth and J.E. Pearson (eds). A Laboratory
Manual for Isolation and Identification of Avian Pathogens. $3^{\text {rd }}$ Ed. American Association of Avian Pathology, Kennett Square, P.A. pp, 103-105.

$$
\text { دراسة مناعية مقارنة على بعض اللقاحات الحية المستضعفة الأحادية والمركبة فى الاجاج }
$$

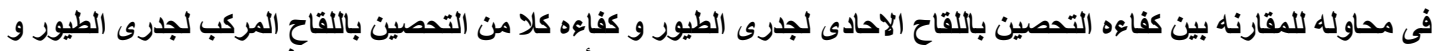

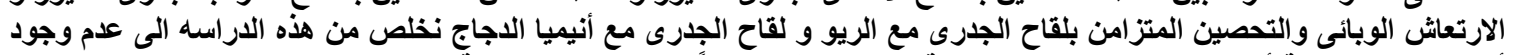

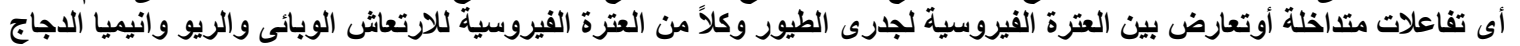

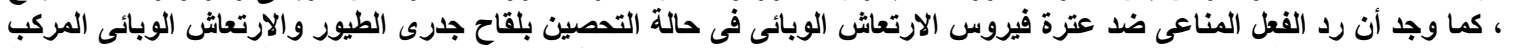

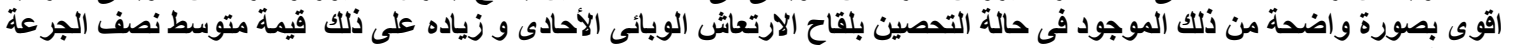

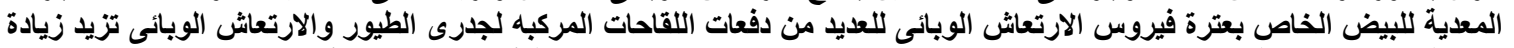

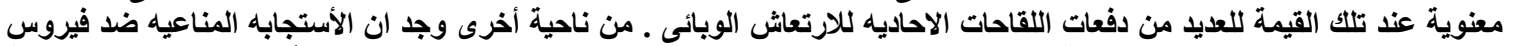

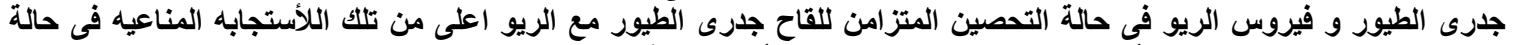

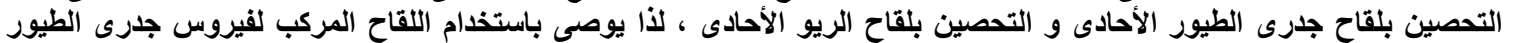

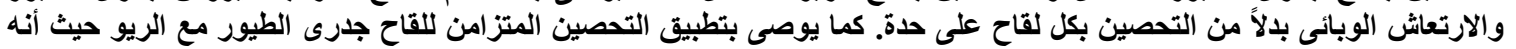

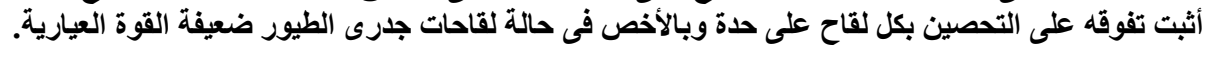

